\title{
Information sources, donation knowledge, and attitudes toward transplant recipients in Australia
}

Context-Knowledge is linked consistently with organ donation attitudes, willingness, and consent. Negative information about donation and the recipients of donation can affect public opinion and donation willingness. However, it is unclear which information sources are most important in forming knowledge, particularly in Australia where little prior research exists.

Objectives-To identify information sources that may inform Australians' organ donation knowledge and attitudes toward transplant recipients.

Participants - 1487 Australian residents aged 18 years or older who completed an online survey.

Main Outcome Measures-Self-reported knowledge, information sources, and attitudes toward transplant recipients.

Results-Participants felt fairly well informed about organ donation, particularly if they registered donation wishes, were female, and were older. More than half reported their driver's license, television news, and discussion with family/friends as donation information sources. However, information sources contributing to knowledge were personal experience, online, hospital, government campaign, discussion with family/friends, Medicare, doctor's surgery, and the newspaper. Differences based on registration status, sex, and age, were found. Discussion with family/friends and movies or television shows, as well as not having seen information in a newspaper or doctor's surgery, contributed to positive attitudes toward recipients, although the variance explained was small.

Conclusions-People felt more informed by personal, medical, and government information sources than by mass media. Family discussion was not only a common information source but also contributed significantly and positively to both donation knowledge and attitudes toward recipients. Further exploration of information sources contributing to donation knowledge and community attitudes toward transplant recipients among young men is needed. (Progress in Transplantation. 2014;24:169-177)

(C2014 NATCO, The Organization for Transplant Professionals doi: http://dx.doi.org/10.7182/pit2014799

\author{
Melissa K. Hyde, BPsych \\ (Hons), PhD, Suzanne K. \\ Chambers, RN, BA, BBehSci \\ (Hons), PhD \\ Griffith University, Brisbane, Australia
}

Corresponding author: Dr Melissa K. Hyde, Griffith Health Institute, Griffith University, 176 Messines Ridge Road, Mt Gravatt, Queensland, 4122, Australia

(e-mail: melissa.hyde@griffith.edu.au)

To purchase electronic or print reprints, contact:

American Association of Critical-Care Nurses 101 Columbia, Aliso Viejo, CA 92656

Phone (800) 899-1712 (ext 532) or

(949) 448-7370 (ext 532)

Fax (949) 362-2049

E-mail reprints@aacn.org
$\mathrm{D}$ espite government and transplant organization initiatives, low rates of organ donation continue to limit the organ supply. In Australia particularly, the discrepancy between the donation rate of 15.1 donors per million population ${ }^{1}$ (one of the lowest in the world) in the face of positive attitudes toward organ donation is difficult to reconcile. Accurate factual knowledge about organ donation (eg, the need for organs, the donation/transplant process) and how informed a person feels generally about donation have been positively associated with donation attitudes, willingness, and donor status/registration; this finding is one of the most widely studied and robust in the literature. ${ }^{2-8}$ On this basis, public education and campaigns to improve knowledge and awareness of donation have been advocated as potential strategies to improve donation rates.

Although knowledge has been linked repeatedly to donation attitudes, willingness, and donor status/ registration, what is less well known is how people's organ donation knowledge is formed. A range of information sources such as the media and personal experience most likely contribute to knowledge..$^{89-12}$ Increased and more recent exposure to information is associated not only with willingness to donate and register 
donation wishes, ${ }^{13,14}$ but also with actual family consent for donation of a loved one's organs. ${ }^{13}$ Yet the evidence regarding the exact nature of the relationship between information sources and knowledge ${ }^{8}$ and the information sources most important in forming knowledge remain unclear. It is the latter aspect that we focus on in the current study in identifying the information sources that may inform Australians' knowledge about organ donation.

International research shows that common sources of information about organ donation include television, newspapers or magazines, radio, the Bureau or Department of Motor Vehicles, health care professionals, family/friends, and campaigns, ${ }^{2,79,13-17}$ with these sources varying depending on the population studied and location. For example, in Spain, ${ }^{16}$ television and radio were reported as key information sources; however, health professionals and family/friends had the most positive impact on donation. In a US study with African Americans,${ }^{17}$ discussion with family (especially for donor card signers) and the Department of Motor Vehicles were the most common information sources.

Very little research exists about Australians' exposure to organ donation information and how this information may inform knowledge. The few studies that could be located suggested that key information sources about organ donation were the media, ${ }^{18}$ knowing a donor or recipient,,$^{18}$ doctors, hospitals, and the Internet. ${ }^{19}$ Trusted information sources included hospitals/ health/medical clinics (particularly for those who were more likely to register as a donor) and family/ friends (especially males). However, $21 \%$ did not know and $16 \%$ did not trust any information source as reliable. ${ }^{19}$ Clearly, there is a need to explore further how the Australian community is informed about organ donation and whether information sources are similar to those reported in international studies.

In addition to information sources having the potential to inform the community's general knowledge about donation, media attention is often focused on organ transplant recipients. For example, newspaper stories commonly focus on the well-being of donors and recipients after transplant. ${ }^{9}$ Media coverage on donation and transplant can be both positive and negative, with negative stories remembered more and used to justify donation attitudes and decisions. ${ }^{11}$ It follows that negative information about donation/transplant or recipients such as unfairness in organ allocation, judgments about recipients' deservingness for transplant, or responsibility for their health condition could adversely affect public opinion and willingness to donate..$^{10,20,21}$

Lack of knowledge about the reasons transplants are needed may also lead to increased associations between particular organs and unhealthy behaviors, which can be exacerbated by media coverage; examples include the association between a liver transplant and alcohol dependency or a lung transplant and smoking ${ }^{20,22,23}$ Such associations have far-reaching implications not only for people's willingness to donate or register ${ }^{21,24}$ but also for treatment and community attitudes toward people with health conditions more broadly. ${ }^{22,25}$ Our second aim then, was to examine Australians' attitudes toward transplant recipients and identify information sources that may inform these attitudes. A third aim, based on prior research, was to explore differences in knowledge and information sources based on demographic characteristics (eg, age, $\operatorname{sex})^{7}$ and donor registration status ${ }^{5,26}$ because there is little consensus regarding these differences. ${ }^{7,15,27}$

\section{Objectives}

Specifically we had the following questions: (1) How informed do people feel about organ donation? (2) What information sources have the community been exposed to and how recently? (3) Which information sources contribute to knowledge and are there differences based on donor registration status, sex, and age? (4) Are the community's attitudes toward transplant recipients positive and do these attitudes differ depending on donor registration status (as found in prior research ${ }^{21}$ )? (5) Which information sources contribute to attitudes toward recipients?

\section{Methods}

\section{Participants and Procedure}

A total of 1487 Australian residents aged 18 years or older residing predominantly in Queensland (53\%) and New South Wales (34\%) completed a 15-minute online survey. After gaining approval from the ethics review board, we used a number of recruitment strategies. Survey invitations were delivered to community residences by using the unaddressed mail service (no residential address required) with a low response rate of $8.88 \%$ (delivery of 4000 flyers resulted in 355 responses; however, it is not possible to verify that all flyers were received as intended), via online university alumni and workplace mailing lists, postings on community websites, and snowballing (response rate could not be calculated).

Surveys were hosted via the university's secure online site from March to August 2010. Responses were anonymous and confidential. Participants entered a prize drawing to win 1 of 7 gift cards (each worth $A \$ 100$ ) to a department or music store.

\section{Measures}

Background Characteristics and Donor Variables. Participants self-reported their age in years by selecting 1 of 3 age categories (18-35, 36-55, $\geq 56$ years) approximating categories used in the Australian and New Zealand Organ Donor Registry Report, ${ }^{28(\mathrm{p} 10)}$ as well as their sex (male, female), ethnicity (white, other), 
religious/spiritual orientation (identify with religion vs not), relationship (in a relationship vs not), and perceived medical eligibility (medically eligible vs not). Participants also reported their donation preference (yes, no, undecided), whether they had registered consent on the Australian Organ Donor Register or discussed donation wishes with their partner/family, and whether they knew an organ/tissue donor or recipient, or personally needed or had received a transplant (all scored yes, no).

Donation Knowledge. A 1-item measure with a 7point response scale measured self-reported donation knowledge, scored from 1 (very poor) to 7 (excellent). ${ }^{27}$

Source of Organ Donation Information. Participants indicated where they had previously seen information about organ donation by selecting from 15 items (multiple information sources could be selected): television news, newspaper, television or radio advertisements, hospital, Medicare office (administers the Australian Organ Donor Register on behalf of the Australian government), online, shopping mall, driver's license (before the register, donation preference was recorded on the license), magazine, personal experience, government campaign (eg, Organ Donor Awareness Week), discussion with a family member or friend, doctor's surgery or medical practice, movies and/or television shows (eg, ER, Grey's Anatomy), and other.

Recency of Organ Donation Information. One item measured when participants had last seen/heard organ donation being promoted in Australia (eg, television, radio, Internet, newspaper, magazine): in the past month, 3 months ago, 6 months ago, 12 months ago, or more than 1 year ago.

Attitudes Toward Organ Transplant Recipients. We used a modified version (to address prior limitations of dichotomous end points and clarity of items) of an attitudes toward transplant recipients scale developed in prior research. ${ }^{20,21}$ Participants were instructed to first think about the type of person who needs an organ transplant and then to rate on a 5-point scale (scored from 1 [not at all true] to 5 [always true]) how descriptive 6 positive and 8 negative statements were of transplant recipients: selfish, ordinary person, substance user, blameworthy for their illness, someone who is similar to me, deserving of an organ transplant, responsible for their illness, smoker, alcohol dependent, deserving of their illness, unfortunate, someone who looks after their health, accountable for their illness, and grateful for a transplant. To create the attitudes toward transplant recipients scale, negative statements were reverse scored and combined with positive statements so that higher scores indicated more positive attitudes. The scale had adequate reliability (Cronbach $\alpha=0.76$ ), with a mean score of 4.01 ( $\mathrm{SD}=0.38$, minimum $=1.86$, maximum $=5.00$ ).

\section{Statistical Analysis}

Cross-tabs $\left(\chi^{2}\right)$ or $t$ tests were used to examine differences in background characteristics and donor variables. Descriptive statistics (percentages) were used to examine the proportions of participants exposed to each source of information on organ donation and the recency of their exposure. Independent groups $t$ test or 1 -way analyses of variance were used to compare means for (1) self-reported knowledge based on donor registration status, sex, and age, and (2) attitudes toward recipients based on registration status. Separate hierarchical multiple regressions were used to identify information sources associated with (1) donation knowledge and (2) attitudes toward transplant recipients. Also, differences in information sources predicting knowledge were explored in regressions for donor registration status (registered vs nonregistered) and combined sex and age groupings (men 18-35 years old, men 36-55 years old, men $\geq 56$ years old, women $18-35$ years old, women $36-55$ year old, women $\geq 56$ years old).

\section{Results}

Background Characteristics and Donor Variables

Respondents were predominantly female (67.4\%), white $(94.5 \%)$, in a relationship $(72.5 \%)$, and less than 55 years old (18-35 years, $34.5 \%$; 36-55 years, $41.7 \%)$. Approximately half (50.8\%) did not identify with a formal religious or spiritual orientation, and most believed that they were medically eligible to donate $(91.6 \%)$. Most wanted to donate their organs upon death $(84.7 \%)$. Although the majority had discussed their donation wishes with their partner/family member (73.4\%), more than half had not registered consent on the Australian Organ Donor Register $(57.7 \%)$. Most participants did not know an organ/tissue donor $(84.9 \%)$ or recipient $(63.7 \%)$ and did not personally need a transplant $(99.7 \%)$, nor had they received a transplant $(99.4 \%)$. Background characteristics, donation preference, communication of consent, and donation experience did not differ significantly according to donor registration status, sex, or age.

\section{Organ Donation Knowledge}

Overall, participants self-reported an above average level of knowledge about organ donation (mean, 4.80; SD, 1.24; range, 1-7). Participants who had registered donation wishes had significantly higher knowledge (mean, 5.14; SD, 1.13; range, 2-7) than nonregistered participants had (mean, 4.56; SD, 1.25; range, $1-7 ; t_{1462}=9.18 ; P<.001$ ). Female (mean, 4.89; $\mathrm{SD}, 1.2$; range, 1-7) rather than male (mean, 4.63; $\mathrm{SD}, 1.30$; range, $\left.1-7 ; t_{1475}=3.78, P<.001\right)$ and older ( $\geq 56$ years old: mean, 4.93 ; SD, 1.17 ; range, $2-7$ ) 
Table 1 Exposure to organ donation information sources overall and comparisons by donor registration status, sex, and age

\begin{tabular}{|c|c|c|c|c|c|c|c|c|c|c|}
\hline \multirow[b]{3}{*}{ Information source } & & & \multicolumn{4}{|c|}{ Donor registration } & \multicolumn{4}{|c|}{ Sex } \\
\hline & \multicolumn{2}{|c|}{$\begin{array}{l}\text { Overall } \\
(\mathrm{N}=1487)\end{array}$} & \multicolumn{2}{|c|}{$\begin{array}{c}\text { Yes } \\
(n=620)\end{array}$} & \multicolumn{2}{|c|}{$\begin{array}{c}\text { No } \\
(\mathrm{n}=847)\end{array}$} & \multicolumn{2}{|c|}{$\begin{array}{c}\text { Male } \\
(\mathrm{n}=483)\end{array}$} & \multicolumn{2}{|c|}{$\begin{array}{c}\text { Female } \\
(\mathrm{n}=997)\end{array}$} \\
\hline & No. & $\%$ & No. & $\%$ & No. & $\%$ & No. & $\%$ & No. & $\%$ \\
\hline News on television & 947 & 63.7 & 410 & 66.1 & 525 & 62.0 & 330 & 68.3 & 611 & 61.3 \\
\hline Newspaper & 634 & 42.6 & 280 & 45.2 & 344 & 40.6 & 224 & 46.4 & 407 & 40.8 \\
\hline Ad on television/radio & 709 & 47.7 & 332 & 53.5 & 370 & 43.7 & 219 & 45.3 & 488 & 48.9 \\
\hline Hospital & 556 & 37.4 & 255 & 41.1 & 297 & 35.1 & 175 & 36.2 & 380 & 38.1 \\
\hline Medicare & 410 & 27.6 & 235 & 37.9 & 173 & 20.4 & 99 & 20.5 & 309 & 31.0 \\
\hline Online & 366 & 24.6 & 181 & 29.2 & 179 & 21.1 & 120 & 24.8 & 245 & 24.6 \\
\hline Shopping center & 50 & 3.4 & 22 & 3.5 & 26 & 3.1 & 13 & 2.7 & 36 & 3.6 \\
\hline Driver's license & 1071 & 72.0 & 456 & 73.5 & 606 & 71.5 & 343 & 71.0 & 724 & 72.6 \\
\hline Magazine & 243 & 16.3 & 109 & 17.6 & 131 & 15.5 & 64 & 13.3 & 177 & 17.8 \\
\hline Personal experience & 270 & 18.2 & 123 & 19.8 & 146 & 17.2 & 93 & 19.3 & 175 & 17.6 \\
\hline Government campaign & 663 & 44.6 & 315 & 50.8 & 339 & 40.0 & 185 & 38.3 & 476 & 47.7 \\
\hline Discuss family/friend & 767 & 51.6 & 346 & 55.8 & 416 & 49.1 & 206 & 42.7 & 558 & 56.0 \\
\hline Doctor's practice & 443 & 29.8 & 207 & 33.4 & 233 & 27.5 & 142 & 29.4 & 300 & 30.1 \\
\hline Movies/television shows & 626 & 42.1 & 267 & 43.1 & 354 & 41.8 & 138 & 28.6 & 485 & 48.6 \\
\hline Other & 97 & 6.5 & 42 & 6.8 & 54 & 6.4 & 30 & 6.2 & 66 & 6.6 \\
\hline
\end{tabular}

rather than younger (18-35 years old: mean, 4.73; SD, 1.23 ; range, $\left.1-7 ; t_{860}=2.41, P=.02\right)$ participants had significantly higher knowledge scores.

\section{Sources of Organ Donation Information}

Key sources of information on organ donation overall reported by more than half of the sample were a person's driver's license, television news, and discussion with family/friends. In addition to these sources, more than $50 \%$ of participants who were registered as organ donors listed advertisements on television/radio and government campaigns as information sources. The 2 information sources reported by more than half of participants who were not registered as organ donors, both male and female, were the driver's license and television news, with females also citing discussion with family/friends as a key information source. More than $50 \%$ of all age categories listed the driver's license and television news as important information sources. More than 50\% of the following age categories listed discussion with family/friend (18-35 and 36-55 years only), advertisements on television /radio (36-55 years only), the newspaper ( $\geq 56$ years only), and movies/ television shows (18-35 years only) as important information sources (Table 1).

\section{Recency of Organ Donation Information}

Overall, respondents had last seen information about or promotion of organ donation in Australia in the month preceding the survey (39.1\%), 3 months prior $(25.6 \%), 6$ months prior (13.8\%), 12 months prior $(6 \%)$, and more than 1 year prior $(15.5 \%)$. A significantly greater proportion of participants who were registered as organ donors $(45.0 \%)$ than nonregistered (35.6\%) had seen information or promotion in the month preceding the survey $(z=3.86, \mathrm{SE}=.03$, $P<.001)$. Males and females and age categories did not differ significantly in the recency of their information exposure.

\section{Information Sources Contributing to Knowledge}

Regressions with information sources predicting self-reported knowledge for the whole sample, as well as comparisons based on donor registration status, and age by sex groupings are presented in Table 2 (including regression weights, variance explained, and $\mathrm{F}$ statistics). For the whole sample, significant information sources contributing to knowledge were personal experience, online, hospital, government campaign, discussion with family/friends, Medicare, doctor's practice, and the newspaper.

For registered and nonregistered respondents, common information sources significantly contributing to knowledge were personal experience, online, and discussion with family/friends. The hospital (registered only), Medicare (nonregistered), and government campaigns (nonregistered) were additional significant contributors. 


\begin{tabular}{|c|c|c|c|c|c|}
\hline \multicolumn{6}{|c|}{ Age, y } \\
\hline \multicolumn{2}{|c|}{$\begin{array}{c}18-35 \\
(n=512)\end{array}$} & \multicolumn{2}{|c|}{$\begin{array}{c}36-55 \\
(n=325)\end{array}$} & \multicolumn{2}{|c|}{$\begin{array}{c}\geq 56 \\
(n=325)\end{array}$} \\
\hline No. & $\%$ & No. & $\%$ & No. & $\%$ \\
\hline 285 & 55.7 & 423 & 68.4 & 235 & 66.8 \\
\hline 175 & 34.2 & 268 & 43.4 & 188 & 53.4 \\
\hline 233 & 45.5 & 316 & 51.1 & 157 & 44.6 \\
\hline 206 & 40.2 & 240 & 38.8 & 108 & 30.7 \\
\hline 155 & 30.3 & 153 & 24.8 & 99 & 28.1 \\
\hline 170 & 33.2 & 132 & 21.4 & 63 & 17.9 \\
\hline 11 & 2.1 & 22 & 3.6 & 16 & 4.5 \\
\hline 352 & 68.8 & 453 & 73.3 & 262 & 74.4 \\
\hline 70 & 13.7 & 96 & 15.5 & 77 & 21.9 \\
\hline 65 & 12.7 & 127 & 20.6 & 78 & 22.2 \\
\hline 219 & 42.8 & 276 & 44.7 & 165 & 46.9 \\
\hline 297 & 58.0 & 309 & 50.0 & 161 & 45.7 \\
\hline 179 & 35.0 & 165 & 26.7 & 97 & 27.6 \\
\hline 272 & 53.1 & 257 & 41.6 & 96 & 27.3 \\
\hline 37 & 7.2 & 45 & 7.3 & 15 & 4.3 \\
\hline
\end{tabular}

someone who looks after their health, and grateful for a transplant. Nonregistered respondents (vs registered) were significantly less likely to believe a recipient was an ordinary person, similar to them, or deserving of a transplant, and significantly more likely to perceive a recipient as responsible for their illness and alcohol dependent (although means were low; Table 3).

\section{Information Sources Contributing to Attitudes Toward Organ Transplant Recipients}

In step 1 of the regression, information sources explained a small but significant $2.5 \%$ (1.6\% adjusted) of variance in attitudes toward recipients $\left(F_{14,1449}=\right.$ $2.68, P=.001)$. Including donor registration status explained a further $1.5 \%$ of variance $\left(F \Delta_{1,1448}=12.97\right.$, $P<.001)$. After entry of all variables, information sources significantly associated with more positive attitudes toward recipients were discussion with family/friends $(\beta=.07)$ and movies/television shows $(\beta=$ .07 ), and not having seen information about organ donation in the newspaper $(\beta=-.08)$ or a doctor's surgery/medical practice $(\beta=-.06)$.

\section{Discussion \\ Summary of Findings}

Overall, participants reported feeling fairly well informed about donation, particularly those who were registered donors, ${ }^{5,26}$ female, and 56 years old or older. The driver's license, television news, and discussion with family/friends were identified by more than $50 \%$ of the sample as the most common sources of information about organ donation. This finding is broadly consistent with prior research suggesting that television and the newspaper along with family discussion are the key sources of information on organ donation. ${ }^{27,13-17}$ The information sources that were commonly reported, however, did not necessarily contribute significantly to knowledge formation. ${ }^{2,16}$ Government (Medicare, government campaign), medical (hospital, doctor's surgery/medical practice), and personal (personal experience, discussion with family/friends) sources, as well as obtaining information from an online source and the newspaper, were significant contributors to knowledge for the whole sample. Information sources associated significantly with knowledge also differed depending on sex and age; particularly, we found that none of the information sources contributed to knowledge for men from 18 to 35 years old.

Notably, media sources did not feature strongly as contributors to knowledge. Similarly, Morgan et $\mathrm{al}^{8}$ reported that it was interpersonal sources (family/ friends, personally knowing a transplant recipient) that had a positive effect on knowledge, rather than media sources. Importantly, our findings accord with 
Table 2 Hierarchical multiple regressions $\left(\beta\right.$ weights ${ }^{a}$ ) with information sources contributing to self-reported organ donation knowledge overall, and comparisons based on registration status, sex, and age groupings

\begin{tabular}{|c|c|c|c|c|c|c|c|c|c|c|}
\hline \multirow[b]{2}{*}{ Step } & \multirow[b]{2}{*}{ Variable } & \multirow[t]{2}{*}{ Overall } & \multicolumn{2}{|c|}{ Donor registration } & \multicolumn{6}{|c|}{ Age (in years) $\times$ sex categories } \\
\hline & & & Yes & No & $\begin{array}{c}18-35 \\
\text { Male }\end{array}$ & $\begin{array}{l}36-55 \\
\text { Male }\end{array}$ & $\begin{array}{l}\geq 56 \\
\text { Male }\end{array}$ & $\begin{array}{c}18-35 \\
\text { Female }\end{array}$ & $\begin{array}{l}36-55 \\
\text { Female }\end{array}$ & $\begin{array}{l}\geq 56 \\
\text { Female }\end{array}$ \\
\hline \multirow[t]{17}{*}{1} & $R^{2}$ & $0.18^{b}$ & $0.14^{b}$ & $0.18^{b}$ & 0.14 & $0.27^{b}$ & $0.30^{b}$ & $0.22^{b}$ & $0.13^{b}$ & $0.33^{b}$ \\
\hline & $F$ & $22.00^{b}$ & $7.25^{b}$ & $13.00^{\mathrm{b}}$ & 1.15 & $4.92^{b}$ & $4.45^{b}$ & $7.72^{b}$ & $4.18^{b}$ & $5.92^{b}$ \\
\hline & $(d f)$ & $(14,1449)$ & $(14,603)$ & $(14,831)$ & $(14,99)$ & $(14,183)$ & $(14,144)$ & $(14,375)$ & $(14,397)$ & $(14,165)$ \\
\hline & Television news & .05 & .04 & .05 & .01 & $.18^{\mathrm{C}}$ & .05 & .05 & .03 & .10 \\
\hline & Newspaper & $.05^{\mathrm{c}}$ & .03 & .07 & .17 & .08 & .14 & .02 & .02 & .03 \\
\hline & Television/radio ad & .00 & .02 & -.01 & -.06 & .07 & .12 & -.06 & -.00 & .09 \\
\hline & Hospital & $.09^{d}$ & $.14^{\mathrm{d}}$ & .06 & .05 & -.03 & .10 & $.14^{\mathrm{d}}$ & .08 & $.19 c$ \\
\hline & Medicare & $.07^{\mathrm{d}}$ & .05 & $.09^{d}$ & .08 & .11 & .01 & .07 & -.03 & $.22^{\mathrm{d}}$ \\
\hline & Online & $.12^{b}$ & $.11^{\mathrm{d}}$ & $.14^{\mathrm{b}}$ & .12 & $.19^{d}$ & .03 & $.17^{\mathrm{b}}$ & $.16^{\mathrm{d}}$ & .01 \\
\hline & Shopping center & .03 & .05 & .02 & -.01 & .02 & .03 & -.04 & .03 & .12 \\
\hline & Driver's license & .03 & .02 & .03 & .08 & .09 & .06 & .07 & .01 & -.13 \\
\hline & Magazine & .03 & .08 & .01 & .03 & .01 & .13 & .06 & .00 & .02 \\
\hline & Personal experience & $.16^{b}$ & $.11^{d}$ & $.20^{\mathrm{b}}$ & -.04 & .11 & $.32^{b}$ & $.13^{d}$ & $.16^{\mathrm{d}}$ & $.26^{\mathrm{b}}$ \\
\hline & Government campaign & $.08^{\mathrm{d}}$ & .06 & $.09^{c}$ & .03 & .01 & .07 & .09 & $.10^{c}$ & -.04 \\
\hline & Discussion with family/friend & $.07^{d}$ & $.09 c$ & $.07^{\mathrm{C}}$ & .04 & .09 & .02 & $.10^{c}$ & .05 & .12 \\
\hline & Doctor's practice & $.05^{\mathrm{C}}$ & .02 & .07 & .02 & $.14^{\mathrm{c}}$ & .11 & .02 & .04 & .02 \\
\hline & Movies/television & -.02 & -.04 & -.01 & -.06 & -.09 & -.15 & .01 & -.01 & .00 \\
\hline \multirow[t]{4}{*}{2} & $R^{2} \Delta$ & $0.03^{b}$ & - & - & $0.04^{c}$ & $0.03^{c}$ & 0.01 & $0.05^{b}$ & $0.02^{d}$ & 0.01 \\
\hline & $F \Delta$ & $53.36^{b}$ & - & - & $4.38^{c}$ & $6.45^{c}$ & 1.30 & $25.96^{b}$ & $8.58^{d}$ & $2.98^{\mathrm{c}}$ \\
\hline & (df) & $(1,1448)$ & - & - & $(1,98)$ & $(1,182)$ & $(1,143)$ & $(1,374)$ & $(1,396)$ & $(1,164)$ \\
\hline & Donor registration status & $.18^{\mathrm{b}}$ & - & - & $.20^{c}$ & $.17 \mathrm{c}$ & -.09 & $.24^{b}$ & $.14^{\mathrm{d}}$ & .11 \\
\hline \multicolumn{11}{|c|}{$\begin{array}{l}\text { a } \beta \text { weights are those presented at the final step of the regression. } \\
\mathrm{b} P<.001 \text {. }\end{array}$} \\
\hline
\end{tabular}

the limited results of prior Australian research, which suggested that doctors, hospitals, and the Internet were prominent information sources (and also trusted sources in the case of doctors and hospitals).$^{19}$ Increasingly, evidence indicates that although health professionals are an underused information source, they may have a positive impact on donation knowledge and decisions. ${ }^{27,16}$

Overall, participants viewed transplant recipients fairly positively; however, when attitudes were compared on the basis of donor registration status, differences in attitudes toward recipients were apparent. ${ }^{21}$ Specifically, compared with participants who had registered their donation wishes, nonregistered participants were less likely to view transplant recipients as ordinary people, unfortunate, or similar to them and more likely to view recipients as being responsible for or deserving of their illness, or to believe that recipients' need for treatment stemmed from prior alcohol misuse. Obtaining organ donation information via discussion with family/friends or movies/television shows but not the newspaper or doctor's practice was associated with more positive attitudes toward recipients. Potentially, this finding may reflect greater emotional engagement with information from important others or entertainment than what could be provided in clinical or factual contexts such as a doctor's practice or newspaper..$^{29,30}$

\section{Study Limitations}

Despite its strengths, results should be interpreted with caution. Participants represent a convenience sample of people who are willing to participate in a survey on organ donation, and are predominantly female, white, and most likely highly educated - a respondent profile that is similar to the profiles in recent Australian studies..$^{21,27,31}$ Although we did not measure education status directly, the sample is most likely well 
Information sources, donation knowledge, and attitudes toward transplant recipients

Table 3 Attitudes toward transplant recipients for the whole sample and by donor registration status

\begin{tabular}{|c|c|c|c|c|c|}
\hline \multirow[b]{3}{*}{ Attitudes toward recipients } & \multicolumn{3}{|c|}{ Mean (SD) } & \multirow[b]{3}{*}{$t(d f)$} & \multirow[b]{3}{*}{$P^{a}$} \\
\hline & \multirow[b]{2}{*}{ Overall } & \multicolumn{2}{|c|}{ Donor registration } & & \\
\hline & & Yes & No & & \\
\hline Selfish & $1.45(0.67)$ & $1.44(0.66)$ & $1.47(0.68)$ & $-0.81(1462)$ & .42 \\
\hline Ordinary person & $4.03(0.97)$ & $4.12(0.91)$ & $3.98(1.00)$ & $2.81(1455)$ & .005 \\
\hline Substance user & $1.98(0.53)$ & $1.96(0.52)$ & $1.99(0.54)$ & $-1.15(1461)$ & .25 \\
\hline Blameworthy for illness & $1.79(0.65)$ & $1.75(0.65)$ & $1.81(0.65)$ & $-1.79(1460)$ & .07 \\
\hline Similar to me & $3.40(1.05)$ & $3.47(1.01)$ & $3.36(1.07)$ & $1.97(1457)$ & .049 \\
\hline Deserving of transplant & $4.07(0.89)$ & $4.15(0.83)$ & $4.03(0.92)$ & $2.62(1458)$ & .009 \\
\hline Responsible for illness & $1.92(0.62)$ & $1.87(0.60)$ & $1.96(0.62)$ & $-2.74(1460)$ & .006 \\
\hline Smoker & $2.07(0.54)$ & $2.05(0.50)$ & $2.08(0.57)$ & $-1.24(1455)$ & .22 \\
\hline Alcohol dependent & $2.03(0.54)$ & $1.98(0.47)$ & $2.06(0.58)$ & $-2.96(1400)$ & .003 \\
\hline Deserving of illness & $1.37(0.73)$ & $1.34(0.72)$ & $1.39(0.74)$ & $-1.39(1456)$ & .17 \\
\hline Unfortunate & $3.77(1.29)$ & $3.83(1.29)$ & $3.73(1.28)$ & $1.37(1458)$ & .17 \\
\hline Looks after their health & $3.03(0.89)$ & $3.08(0.89)$ & $3.00(0.88)$ & $1.74(1459)$ & .08 \\
\hline Accountable for illness & $1.98(0.76)$ & $1.95(0.77)$ & $2.00(0.75)$ & $-1.25(1458)$ & .21 \\
\hline Grateful for transplant & $4.41(0.78)$ & $4.46(0.69)$ & $4.39(0.81)$ & $1.88(1460)$ & .06 \\
\hline
\end{tabular}

educated given that recruitment efforts included university alumni lists, workplaces, and snowballing whereby participants may have forwarded the survey to people with a similar educational background. The cross-sectional nature of this study prevents inferences about causality, and future prospective research is needed. Responses may also be limited by recall of content about organ donation and exposure to information sources, with recall of information potentially greater for people who are registered donors. ${ }^{31}$ Further, we used a subjective assessment of how informed people feel they are about organ donation, rather than an objective assessment of their knowledge of donation facts. Using both types of measures in future research would give a clearer picture about the information sources associated with factual knowledge and whether these differ from self-reported levels of knowledge.

\section{Study Implications}

With these limitations in mind, our study findings suggest some directions for future research and practice. Participants felt more informed if they had seen/ heard organ donation information from personal, medical, or government sources rather than mass media. Discussion with family/friends was not only a common information source but also contributed significantly and positively to donation knowledge and attitudes toward transplant recipients. The focus on family discussion in Australia, most recently with the "OK" campaign,$^{32}$ has been to encourage people to tell their family their donation wishes, which is vital for the purposes of increasing consent. Our results suggest that, in addition to this message, people should be encouraged to talk about organ donation more generally and to discuss others who are known to them personally or publicly who may have donated or received the benefits of a transplant.

Although we gained some insight into the information sources that may contribute to knowledge for middle aged (36-55 year old) and older ( $\geq 56$ years old) men, such as television news, online, and the doctor's practice and especially personal experience for older men, none of the information sources were associated with young men's (18-35 years) knowledge. Therefore, it is not clear how young men are being informed about organ donation or how they can be encouraged to engage in discussion. Thompson et $\mathrm{al}^{33}$ suggest that organ donation campaigns could appeal to a man's status or his ability to take care of his family and community after death. With this in mind, it may be useful to more actively engage advocates for donation in Australia that young men can relate to. Alternatively, it may be worth capitalizing further on information dissemination points such as the Department of Motor Vehicles (Department of Transport and Main Roads in Australia where information about the donor registry is given when driver licenses are issued or renewed). The driver's license was the most common information source in this study, and the Department of Motor Vehicles may be ideal to engage young 
men in discussion with family/friends (eg, while waiting in line) or provide the opportunity for them to ask questions/seek further information..$^{34} \mathrm{~A}$ greater proportion of the donor population in Australia are men, ${ }^{28}$ men are less likely to discuss donation, ${ }^{33}$ and in this study reported feeling less informed about organ donation. Accordingly, it is essential to improve our understanding of how men, especially young men, are informed about, make decisions about, and communicate consent for organ donation.

\section{Conclusion}

Attitudes toward transplant recipients were more negative among people who had not registered their donation wishes in this study. Increasing perceived similarity between the community as potential donors and transplant recipients by focusing on shared life experiences and providing examples of recipients who do not fit the negative image to increase heterogeneity may be helpful..$^{20,21}$ Furthermore, information sources explained only a small percentage of the variance in attitudes toward recipients. Qualitative and experimental studies to explore how attitudes toward recipients may be formed and the information sources that are most influential in this process are needed. Continuing to understand the information sources that contribute to the creation of accurate knowledge about organ donation and positive attitudes toward organ recipients has the potential to affect not only willingness and consent for donation of one's own and others organs, but ultimately improved access to lifesaving or enhancing treatment for those suffering waiting for an organ transplant.

\section{Note}

The data were collected while the first author was employed at Queensland University of Technology, Brisbane, Australia.

\section{Financial Disclosures}

None reported.

\section{References}

1. DonateLife. Performance Report June 2012. http://www .donatelife.gov.au/media/docs/Performance_Report_Jan -June_2012.pdf. Accessed July 3, 2013.

2. Saub EJ, Shapiro J, Radecki S. Do patients want to talk to their physicians about organ donation? Attitudes and knowledge about organ donation: a study of Orange County, California residents. J Community Health. 1998;23(6):407-417.

3. Falomir-Pichastor JM, Berent JA, Pereira A. Social psychological factors of post-mortem organ donation: a theoretical review of determinants and promotion strategies. Health Psychol Rev. 2013;7(2):202-247.

4. Haustein SV, Sellers MT. Factors associated with (un)willingness to be an organ donor: importance of public exposure and knowledge. Clin Transplant. 2004;18(2):193-200.

5. Horton RL, Horton PJ. Knowledge regarding organ donation: identifying and overcoming barriers to organ donation. Soc Sci Med. 1990;31(7):791-800.
6. Irving MJ, Tong A, Jan S, et al. Factors that influence the decision to be an organ donor: a systematic review of the qualitative literature. Nephrol Dial Transplant. 2012;27(6):2526-2533.

7. Sander SL, Miller BK. Public knowledge and attitudes regarding organ and tissue donation: an analysis of the northwest Ohio community. Patient Educ Couns. 2005;58(2):154-163.

8. Morgan SE, Stephenson MT, Harrison TR, Afifi WA, Long SD. Facts versus 'feelings': how rational is the decision to become an organ donor? J Health Psychol. 2008;13(5):644-658.

9. Feeley TH, Vincent D 3rd. How organ donation is represented in newspaper articles in the United States. Health Commun. 2007;21(2):125-131.

10. Matesanz R. Organ donation, transplantation, and mass media. Transplant Proc. 2003;35(3):987-989.

11. Morgan SE, Harrision TR, Long SD, Afifi WA, Stephenson MS, Reichert T. Family discussions about organ donation: how the media influences opinions about donation decisions. Clin Transplant. 2005;19(5):674-682.

12. Quick BL, Meyer KR, Kim do K, et al. Examining the association between media coverage of organ donation and organ transplantation rates. Clin Transplant. 2007;21(2):219-223.

13. Rodrigue JR, Cornell DL, Howard RJ. Relationship of exposure to organ donation information on attitudes, beliefs, and donation decision of next of kin. Prog Transplant. 2009;19(2): 173-179.

14. Spigner C, Weaver M, Cardenas V, Allen MD. Organ donation and transplantation: ethnic differences in knowledge and opinions among urban high school students. Ethn Health. 2002; $7(2): 87-101$.

15. Feeley TH, Servoss TJ. Examining college students' intentions to become organ donors. J Health Commun. 2005;10(3):237-249.

16. Conesa C, Rios Zambudio A, Ramirez P, Canteras M, Rodriguez MM, Parilla P. Influence of different sources of information on attitude toward organ donation: a factor analysis. Transplant Proc. 2004;36(5):1245-1248.

17. Morgan SE, Cannon T. African Americans' knowledge about organ donation: closing the gap with more effective persuasive message strategies. J Natl Med Assoc. 2003;95(11):1066-1071.

18. Hardie I, Conomos M, Higgins C, Smithurst B. Attitudes of drivers towards organ donation. Transplant Proc. 1992;24(1):180.

19. Campbell Research \& Consulting. Community Perceptions on Organ and Tissue Donation for Transplantation. Campbell Research \& Consulting Pty Ltd: Victoria, Australia; 2006.

20. Hyde MK, White KM. Student and community perceptions about organ donors, non-donors and transplant recipients. $J$ Commun Appl Soc Psychol. 2009;19(2):125-141.

21. Hyde MK, White KM. A comparison of registered and unregistered organ donors' perceptions about transplant recipients. Clin Transplant. 2011;25(3):444-449.

22. Chapple A, Ziebland S, McPherson A. Stigma, shame, and blame experienced by patients with lung cancer: qualitative study. BMJ. 2004;328(7454):1470.

23. Ubel PA, Jepson C, Baron J, Mohr T, McMorrow S, Asch DA. Allocation of transplantable organs: do people want to punish patients for causing their illness? Liver Transpl. 2001;7(7): 600-607.

24. Tong A, Howard K, Jan S, et al. Community preferences for the allocation of solid organs for transplantation: a systematic review. Transplantation. 2010;89(7):796-805.

25. Chambers SK, Dunn J, Occhipinti S, et al. A systematic review of the impact of stigma and nihilism on lung cancer outcomes. BMC Cancer. 2012;12:184.

26. Morgan SE, Miller JK. Communicating about gifts of life: the effect of knowledge, attitudes, and altruism on behavior and behavioral intentions regarding organ donation. $J \mathrm{Appl} \mathrm{Com}-$ mun Res. 2002;30(2):163-178.

27. Hyde MK, White KM. Young Australian adults' knowledge and beliefs about organ donation. Prog Transplant. 2007;17(3): 220-227.

28. Excell L, Marion V, Russ G. ANZOD Registry Report 2012. Adelaide, South Australia: Australia and New Zealand Organ Donation Registry; 2012.

29. Movius L, Cody M, Huang G, Berkowitz M, Morgan S. Motivating television viewers to become organ donors. Cases Pub 
Information sources, donation knowledge, and attitudes toward transplant recipients

Health Commun Mark. 2007. http://sphhs.gwu.edu/departments $/ \mathrm{pch} / \mathrm{phcm} /$ casesjournal/volume1/peer-reviewed/cases_1_08.pdf. Accessed March 25, 2014.

30. Morgan SE, Harrison TR, Chewning L, Davis L, Dicorcia M. Entertainment (mis)education: the framing of organ donation in entertainment television. Health Commun. 2007;22(2):143-151.

31. Newton JD, Burney S, Hay M, Ewing MT. A profile of Australian adults who have discussed their posthumous organ donation wishes with family members. J Health Commun. 2010; 15(5):470-486.
32. DonateLife (Canberra, ACT). Let your family know your organ donation wishes - OK? Transplant J Australia. 2010; 19:20.

33. Thompson TL, Robinson JD, Kenny RW. Gender differences in family communication about organ donation. Sex Roles. 2003; 49:587-596.

34. Rodrigue JR, Krouse J, Carroll C, Giery KM, Fraga Y, Edwards E. A Department of Motor Vehicles intervention yields moderate increases in donor designation rates. Prog Transplant. 2012;22(1):18-24. 
Copyright of Progress in Transplantation is the property of American Association of CriticalCare Nurses and its content may not be copied or emailed to multiple sites or posted to a listserv without the copyright holder's express written permission. However, users may print, download, or email articles for individual use. 